International Journal of Physical Sciences and Engineering
Available online at www.sciencescholar.us
Vol. 4 No. 2, August 2020, pages: $1-13$
e-ISSN : 2550-6943, p-ISSN : 2550-6951
https://doi.org/10.29332/ijpse.v4n2.433

\title{
Rare Earth Ion Contribution in Barium Hexaferrite Structure to a Change of Magnetocrystalline Anisotropy to Improving Its Magnetic Properties
}

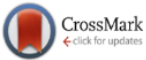

I Gusti Agung Putra Adnyana a ${ }^{\text {a }}$ Ketut Sukarasa ${ }^{\mathrm{b}}$, Wisnu Ari Adi c

Manuscript submitted: 09 June 2020, Manuscript revised: 18 June 2020, Accepted for publication: 27 July 2020

Corresponding Author ${ }^{\text {a }}$

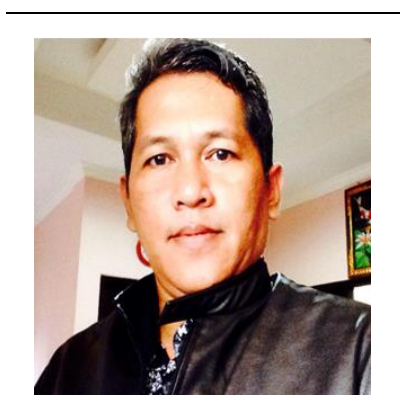

Keywords

barium hexaferrite;

coercivity;

magnetic;

rare earth;

structure;

\section{Abstract}

Rare earth ion contribution in barium hexaferrite structure to a change of magneto-crystalline anisotropy to improving its magnetic properties has been investigated. A series of simples of $\mathrm{Ba}_{1-\mathrm{x}} \mathrm{Ce}_{\mathrm{x}} \mathrm{Fe}_{12} \mathrm{O}_{19}$ with the variation of $\mathrm{x}(\mathrm{x}=$ 0.0-0.5) were prepared by solid-state reactions using mechanical deformation techniques. The oxide materials used for sample preparation are $\mathrm{BaCO}_{3}, \mathrm{Fe}_{2} \mathrm{O}_{3}$, and $\mathrm{CeO}_{2}$ with the ratio of material used is adjusted to the stoichiometric calculation for variations of $\mathrm{Ce}^{4+}$ substitution. The phase identification results show that the reaction took place perfectly and successfully formed a singlephase $\mathrm{Ba}_{1-\mathrm{x}} \mathrm{Ce}_{\mathrm{x}} \mathrm{Fe}_{12} \mathrm{O}_{19}$ namely at the composition $\mathrm{x}=0$ and $\mathrm{x}=0.1$. while for the composition $x>0.1$, it is formed in three phases. Particle morphology in the composition $\mathrm{x}=0$ and $\mathrm{x}=0.1$ has very good and uniform particle homogeneity across the surface of the sample in the form of polygonal particles. So the substitution of Ce atoms into the barium hexaferrite structure is only able at the composition limit $x=0.1$. In the composition $x=0.1$ has been able to increase the coercivity and magnetization fields. It can be concluded that the permanent magnet with the composition $\mathrm{Ba}_{0,9} \mathrm{Ce}_{0.1} \mathrm{~F}_{12} \mathrm{O}_{19}$ gives the best results.
\end{abstract}

International Journal of Physical Sciences and Engineering (C) 2020.

This is an open access article under the CC BY-NC-ND license (https://creativecommons.org/licenses/by-nc-nd/4.0/).

\section{Contents}

Abstract

1 Introduction.

2 Materials and Methods

3 Results and Discussions

a Physics Study Program, Faculty of Mathematics and Natural Sciences, Udayana University, Badung, Bali, Indonesia

b Physics Study Program, Faculty of Mathematics and Natural Sciences, Udayana University, Badung, Bali, Indonesia

c Centre for Science and Technology of Advanced Materials, BATAN, Puspiptek Serpong, South Tangerang, Indonesia 


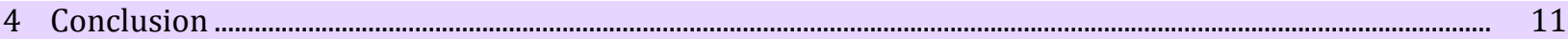

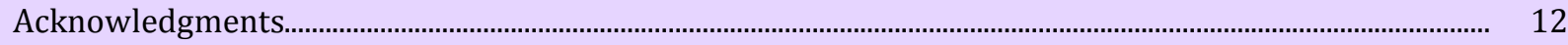

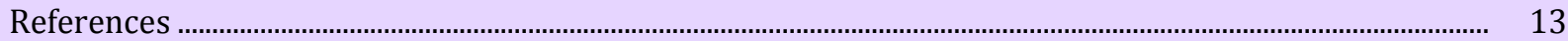

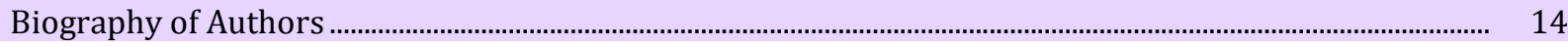

\section{Introduction}

Permanent magnets are materials that have quite extensive applications in line with the development of the industrial era 4.0, which emphasizes digital economic patterns, artificial intelligence, big data, automation, robotics, cloud computing, and others. The development of the industrial era 4.0 is also known as the trend of industrial automation, which indirectly uses permanent magnet components. There are two types of permanent magnet materials currently being developed, namely traditional types of magnets such as iron, AlNiCo, and ceramic magnets (ferrite); and modern types of magnets, Sm-Co and Nd-Fe-B (Purwani et al., 2019; Haritsah et al., 2019; Idris \& Osman, 2013). Of all the types of permanent magnets, ferrite-based magnets or known as barium hexaferrite $\left(\mathrm{BaFe}_{12} \mathrm{O}_{19}\right)$ which is the most economical magnet for production costs. Ferrite-based permanent magnets have the advantage of being the highest curie temperature up to $750^{\circ} \mathrm{C}$, corrosion resistance, and relatively high mechanical strength. However, this type of ferrite magnet has low product energy, generally caused by the magnetocrystalline anisotropy field of this material is still relatively low, resulting in a low coercivity field value. While the magnetic dipole moment of magnetism with the barium hexaferrite system does not change, causing remanence magnetization to remain unchanged. However, the energy of this material product is still possible to be improved through engineering. Judging from these aspects, it is necessary to make efforts to improve the permanent magnetic properties of the ferrite system by substituting rare earth metal ions into the system. Two things are expected to be achieved through the substitution of these rare earth metal ions, namely the presence of rare earth metal ions can increase magneto-crystalline anisotropy (Fisher et al., 2016) and can increase the number of magnetic dipole moments in which ground metal spin is rarely present in the f orbital configuration (Manaf et al., 1993). Thus this extraordinary combination of rare earth metals and transition metals is expected to produce permanent magnet materials with high performance and high energy products. Previous researchers have tried to substitute some rare earth or transition metals into this system material (Haxel, 2002; Zepf, 2013; Nakamura et al., 2011). In previous studies, the substitution of rare-earth ions of lanthanum La into the ferrite system

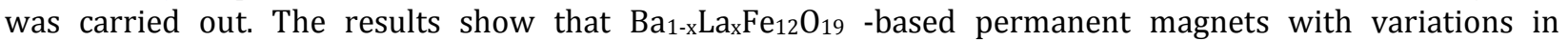
composition ( $\mathrm{x}=0$; $0.02 ; 0.04$; and 0.08$)$ have been successfully made, where the effect of lanthanum substitution into barium atoms can increase the number of magnetic domains shown by an increase in the coercivity value of the material as the composition of $\mathrm{x}$ increases (Adnyana et al., 2019). The best product energy is obtained at the composition $\mathrm{x}=0.04$ with the empirical formulation $\mathrm{Ba}_{0,96} \mathrm{La} a_{00} \mathrm{Fe}_{12} \mathrm{O}_{19}$. According to S. V. Trukhanov reports that this hexaferrite has a changed coercivity field due to the contribution of magnetocrystalline to anisotropic field energy and the behavior of this material is discussed based on crystallite size, density, and porosity.

However, any permanent magnets produced are inseparable from the availability of raw materials, namely iron oxide, barium carbonate, and rare earth metals. In Indonesia, the availability of iron oxide, barium carbonate, and rare earth metals as raw materials for making permanent magnets can be obtained in abundance. That means Indonesia is also a potential country to produce rare earth metals besides China.

A real effort has been made in optimizing the process of making ferrite-based permanent magnets with facilities owned and utilizing local natural resources. The objectives to be achieved in this research are to synthesize and characterize $\mathrm{Ba}_{1-\mathrm{x}} \mathrm{Ce}_{\mathrm{x}} \mathrm{Fe}_{12} \mathrm{O}_{19}$ permanent magnets with $(\mathrm{x}=0.0,0.1,0.2,0.3,0.4$, and 0.5$)$. The method used is a solid reaction through mechanical deformation techniques. The success parameter of the results of this sample making is the formation of the $\mathrm{BaFe}_{12} \mathrm{O}_{19}$ phase in the sample. The discussion focused on phase formation and study of structural parameters using x-ray diffraction and supported by spectroscopy facilities and their magnetic properties. Besides that, it is also learned about the mechanism of increasing the anisotropic field to produce permanent magnets with higher product energy. 


\section{Materials and Methods}

A series simples of $\mathrm{Ba}_{1-\mathrm{x}} \mathrm{Ce}_{\mathrm{x}} \mathrm{Fe}_{12} \mathrm{O}_{19}$ with variation of $\mathrm{x}(\mathrm{x}=0.0,0.1,0.2,0.3,0.4,0.5)$ were prepared by solid state reactions using mechanical deformation techniques. The oxide materials used for sample preparation are $\mathrm{BaCO}_{3}, \mathrm{Fe}_{2} \mathrm{O}_{3}$, and $\mathrm{CeO}_{2}$. Stoichiometric calculations for variations of $\mathrm{Ce}^{4+}$ substitution are shown in Table 1.

Table 1

The stoichiometry calculations of $\mathrm{Ba}_{1-x} \mathrm{La}_{x} \mathrm{Fe}_{12} \mathrm{O}_{19}$

\begin{tabular}{ccccc}
\hline \multirow{2}{*}{$\begin{array}{c}\text { Composition } \\
\text { of } x\end{array}$} & samples & \multicolumn{3}{c}{ mass of raw materials (gram) } \\
\cline { 3 - 5 } & & $\mathrm{BaCO}_{3}$ & $\mathrm{Fe}_{2} \mathrm{O}_{3}$ & $\mathrm{CeO}_{2}$ \\
\hline 0 & $\mathrm{BaFe}_{12} \mathrm{O}_{19}$ & 1.821 & 8.843 & 0.000 \\
0.1 & $\mathrm{Ba}_{0.9} \mathrm{Ce}_{0.1} \mathrm{Fe}_{12} \mathrm{O}_{19}$ & 1.639 & 8.840 & 0.079 \\
0.2 & $\mathrm{Ba}_{0.8} \mathrm{Ce}_{0.2} \mathrm{Fe}_{12} \mathrm{O}_{19}$ & 1.456 & 8.838 & 0.159 \\
0.3 & $\mathrm{Ba}_{0.7} \mathrm{Ce}_{0.3} \mathrm{Fe}_{12} \mathrm{O}_{19}$ & 1.274 & 8.836 & 0.238 \\
0.4 & $\mathrm{Ba}_{0.6} \mathrm{Ce}_{0.4} \mathrm{Fe}_{12} \mathrm{O}_{19}$ & 1.092 & 8.834 & 0.317 \\
0.5 & $\mathrm{Ba}_{0.5} \mathrm{Ce}_{0.5} \mathrm{Fe}_{12} \mathrm{O}_{19}$ & 0.909 & 8.831 & 0.397 \\
\hline
\end{tabular}

Mechanical deformation technique is a mechanical milling technology in which all raw materials are weighted according to their respective compositions, then mixed and ground using a high-energy milling device PW1000di for 5 hours in a $50 \mathrm{~mL}$ ethanol environment (Akmal Johan et al., 2019). The ratio of the mass of the milling balls (10 mm diameter) to the material mass is 2:1. After the milling mixture is dried in an oven at $100^{\circ} \mathrm{C}$ for 6 hours, the sample is manually crushed again using mortal agate. The resulting powder is compacted into tablet form with a compacting pressure of 7000 psi. The tablet form samples were then sintered using a furnace at $1200^{\circ} \mathrm{C}$ for 2 hours (Taryana et al., 2019; Terakado \& Masuda, 1988). Furthermore, each sample is characterized following the objectives to be achieved in this study.

Particle morphology and elemental composition analysis were carried out using SEM-EDS. Grain morphology was observed with an optical microscope (MO) Hitachi TM-3000. Samples for all compositions were smoothed to determine X-ray diffraction patterns measured using a PANalytical XPert Pro X-ray diffractometer using an X-ray.tube.with a wavelength of $\mathrm{CuK \alpha}=1.54056 \AA$ and a step size of 0.02 . The resulting peak data or X-ray diffraction profile was analyzed in terms of cell unit volume, atomic density, lattice parameters, and cationic distribution using the Rietveld method available with GSAS software (Toby, 2001). While testing the magnetic properties were measured using a Physics 255 brand permeagraph with a range of -1.5 Tesla to 1.5 Tesla.

\section{Results and Discussions}

Barium hexagonal ferrite samples with $\mathrm{Ce}^{4+}$ substitution in the $\mathrm{Ba}_{1-\mathrm{x}} \mathrm{Ce}_{\mathrm{x}} \mathrm{Fe}_{12} \mathrm{O}_{19}$ system for $\mathrm{x}=0.0-0.5$ have been investigated. Figure 1 shows the results of XRD measurements for the six samples. The results of the qualitative analysis showed that all samples had a barium hexaferrite phase with space group P63/mmc according to the open database crystallographic data no. 1008841 (Obradors et al., 1985; Lin \& Jimmy, 1998; Greaves et al., 1989). Two samples have a single phase, they are samples with $\mathrm{x}=0.0$ and $\mathrm{x}=0.1$, while for $\mathrm{x}>0.1$ consists of multiple phases.

Adnyana, I. G. A. P., Sukarasa, I. K., \& Adi, W. A. (2020). Rare earth ion contribution in barium hexaferrite structure to a change of magnetocrystalline anisotropy to improving its magnetic properties. International Journal of Physical Sciences and Engineering, 4(2), 1-13. https://doi.org/10.29332/ijpse.v4n2.433 


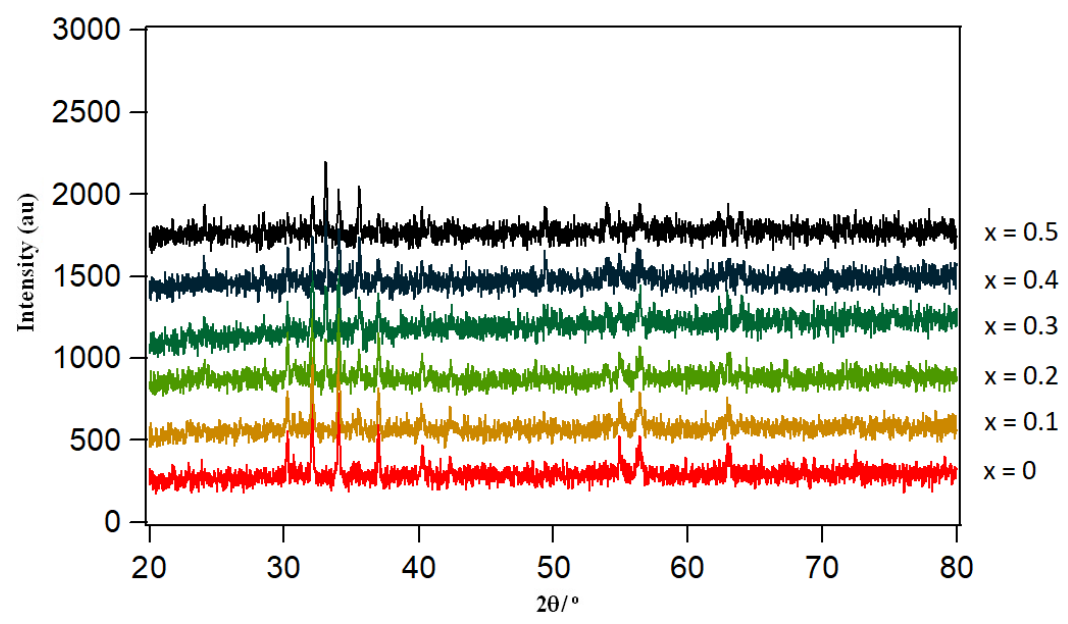

Figure 1. XRD pattern of $\mathrm{Ba}_{1-\mathrm{x}} \mathrm{Ce}_{\mathrm{x}} \mathrm{Fe}_{12} \mathrm{O}_{19}$ sample $(\mathrm{x}=0.0-0.5)$

The results of phase identification using the Match program show that the reaction was perfect and succeeded in forming a single-phase $\mathrm{Ba}_{1-\mathrm{x}} \mathrm{Ce}_{\mathrm{x}} \mathrm{Fe}_{12} \mathrm{O}_{19}$ namely at the composition $\mathrm{x}=0$ and $\mathrm{x}=0.1$, whereas for composition $\mathrm{x}>0.1$, the sample could not react perfectly so the sample was thought to consist of three phases, namely phases $\mathrm{BaFe}_{12} \mathrm{O}_{19}, \mathrm{Fe}_{2} \mathrm{O}_{3}$ and $\mathrm{CeO}_{2}$. Based on the results of this phase identification, it is known that for $\mathrm{x}=0.1$, which means that there are about $10 \%$ of cerium atoms thought to succeed in replacing some of the $\mathrm{Ba}$ atoms in the $\mathrm{BaFe}_{12} \mathrm{O}_{19}$ structure, and for $\mathrm{x}>0.1$ it's suspected that cerium atoms are no longer able to substitute some $\mathrm{Ba}$ atoms causing the cerium atoms to come out to form the $\mathrm{CeO}_{2}$ phase and excess composition of $\mathrm{Fe}_{2} \mathrm{O}_{3}$.

To find out these changes atomically, quantitative analysis is required using the GSAS program so that it can see changes in the parameters of the number of mass fractions formed and the crystal structure by the substitution of Ce into Ba atoms. In Figure 2 shows the results of refinement of XRD patterns using the GSAS program from the $\mathrm{Ba}_{1-\mathrm{x}} \mathrm{Ce}_{\mathrm{x}} \mathrm{Fe}_{12} \mathrm{O}_{19}$ sample with composition variations $(\mathrm{x}=0.0-0.5)$.

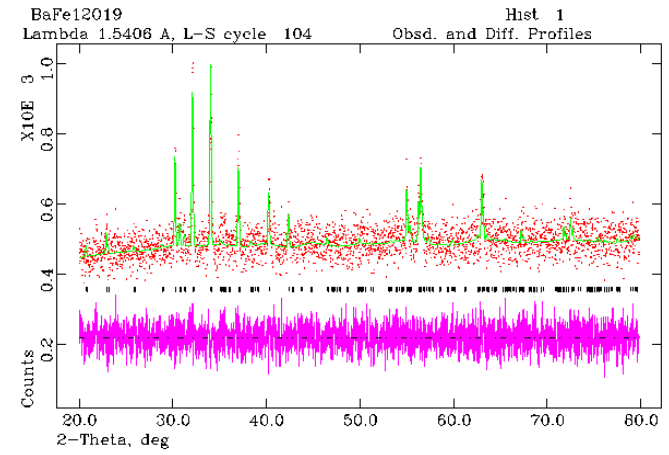

(A) $\mathrm{x}=0$

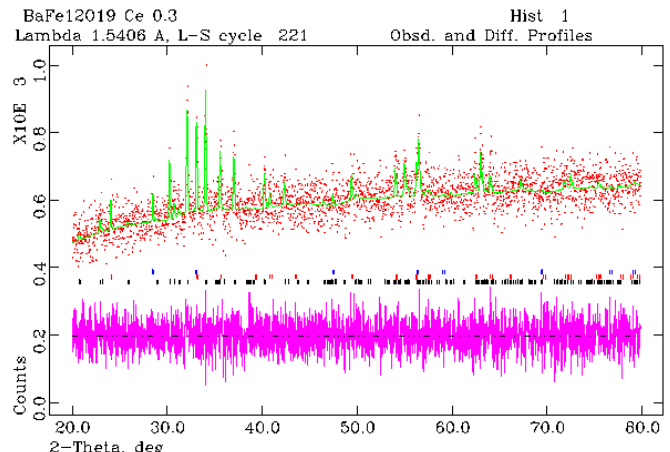

(D) $x=0.3$ 


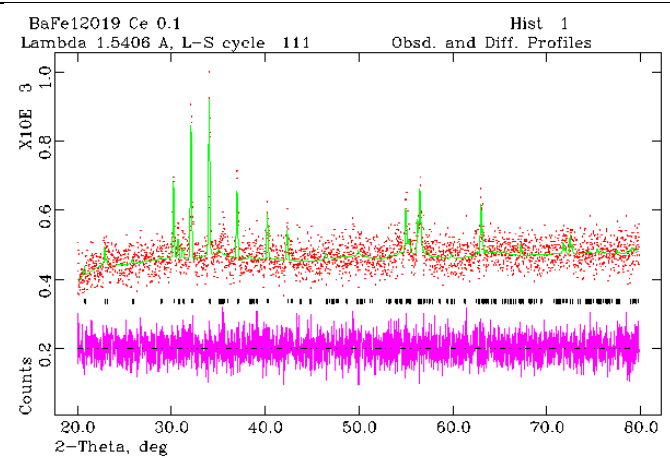

(B) $\mathrm{x}=0.1$

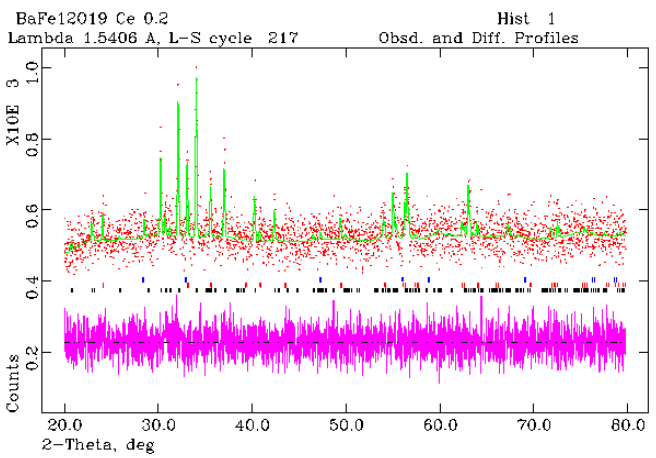

(C) $\mathrm{x}=0.2$

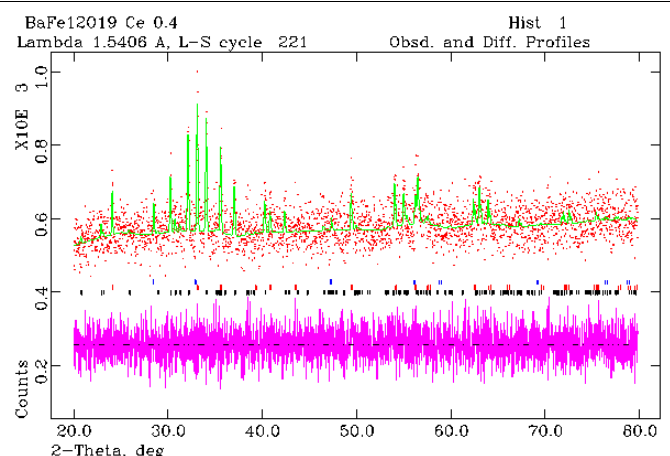

(E) $\mathrm{x}=0.4$

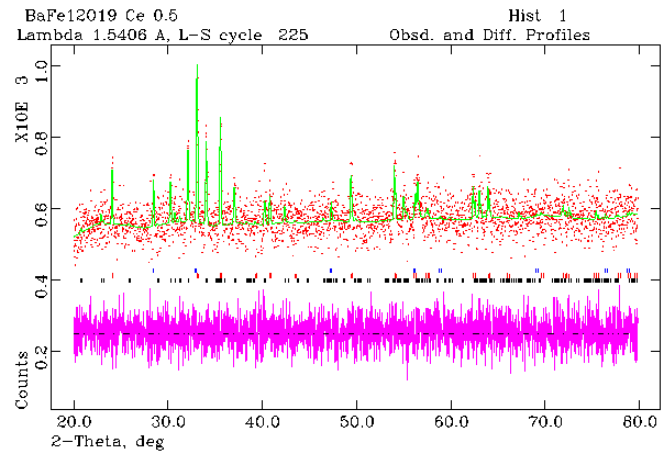

(F) $\mathrm{x}=0.5$

Figure 2. The results of refinement of XRD patterns of $\mathrm{Ba}_{1-\mathrm{x}} \mathrm{Ce}_{\mathrm{x}} \mathrm{Fe}_{12} \mathrm{O}_{19}$ samples $(\mathrm{x}=0.0-0.5)$

Figures 2 (A) and 2 (B) are the patterns for $\mathrm{x}=0$ and 0.1 which have formed a peak of diffraction Bragg with a single-phase following the $\mathrm{BaFe}_{12} \mathrm{O}_{19}$ structure. Figure 2 (C-F) is the result of an improvement in the XRD pattern for $\mathrm{x}>0.1$. The figure shows the presence of three peaks of the Bragg diffraction phase, which follows the structure of $\mathrm{BaFe}_{12} \mathrm{O}_{19}, \mathrm{Fe}_{2} \mathrm{O}_{3}$, and $\mathrm{CeO}_{2}$, seems to increase the mass fraction content as $\mathrm{x}$ composition increases. Quantitative and qualitative analysis refers to the Crystallography Open Database (COD: 1008841) for the $\mathrm{BaFe}_{12} \mathrm{O}_{19}$ phase, and (AMCSD: 180909) for the $\mathrm{Fe}_{2} \mathrm{O}_{3}$ and $\mathrm{LaFeO}_{3}$ phases. A complete summary of the $\mathrm{X}$-ray diffraction pattern refinement results from the $\mathrm{Ba}_{1-\mathrm{x}} \mathrm{Ce}_{\mathrm{x}} \mathrm{Fe}_{12} \mathrm{O}_{19}$ sample with variations .in.composition ( $\mathrm{x}$ $=0.0-0.5$ ) for all samples is shown in Table 2 .

Table 2

Value of fit criteria (Rwp), structural parameters, goodness of fit $(\chi 2)$ and phase mass fraction formed in Ba 1 ${ }_{x} \mathrm{Ce}_{\mathrm{x}} \mathrm{Fe}_{12} \mathrm{O}_{19}$ samples with variations .in.composition $(\mathrm{x}=0.0-0.5)$.

- $\mathrm{x}=0$

\begin{tabular}{|c|c|c|c|c|c|c|c|c|}
\hline wRp & 7.07 & & & $\chi^{2}$ (Chi squ & \begin{tabular}{l|l} 
red) & $:$ \\
\end{tabular} & 1.501 & & \\
\hline \multirow{2}{*}{ Phase } & \multirow{2}{*}{ System } & \multirow{2}{*}{ SG } & \multicolumn{3}{|c|}{ Lattice parameters $(\AA)$} & V & $\rho$ & Fraction \\
\hline & & & $\mathrm{a}$ & $\mathrm{b}$ & c & $\left(\AA^{3}\right)$ & $\left(\mathrm{g} / \mathrm{cm}^{3}\right)$ & $(\%)$ \\
\hline $\mathrm{BaFe}_{12} \mathrm{O}_{19}$ & Hexagonal & $\mathrm{P} 63 / \mathrm{mmc}$ & $5.8907(8)$ & $5.8907(8)$ & 23.197(4) & $697.1(2)$ & 5.774 & 100.00 \\
\hline
\end{tabular}

- $\quad \mathrm{x}=0.1$

\begin{tabular}{|c|c|c|c|c|c|c|c|c|}
\hline wRp & \begin{tabular}{l|l}
$:$ & 7.04 \\
\end{tabular} & & & $\chi^{2}$ (Chi squa & ed) & & & \\
\hline \multirow{2}{*}{ hase } & \multirow{2}{*}{ System } & \multirow{2}{*}{ SG } & \multicolumn{3}{|c|}{ Lattice parameters $(\AA)$} & V & $\rho$ & $\begin{array}{c}\text { Fractio } \\
n\end{array}$ \\
\hline & & & $\mathrm{a}$ & $\mathrm{b}$ & c & $\left(\AA^{3}\right)$ & $\left(\mathrm{g} / \mathrm{cm}^{3}\right)$ & (\%) \\
\hline $\mathrm{Ba}_{0.9} \mathrm{Ce}_{0.1} \mathrm{Fe}_{12} \mathrm{O}_{1}$ & Hexagona & $\mathrm{P} 63 / \mathrm{m}$ & $5.8929(8)$ & $5.8929(8)$ & $23.208(5)$ & $697.9(2)$ & 5.767 & 100.00 \\
\hline
\end{tabular}

Adnyana, I. G. A. P., Sukarasa, I. K., \& Adi, W. A. (2020). Rare earth ion contribution in barium hexaferrite structure to a change of magnetocrystalline anisotropy to improving its magnetic properties. International Journal of Physical Sciences and Engineering, 4(2), 1-13. https://doi.org/10.29332/ijpse.v4n2.433 
9 1 $\mathrm{mc}$

- $\mathrm{x}=0.2$

\begin{tabular}{|c|c|c|c|c|c|c|c|c|}
\hline wRp & 6.70 & & & (Chi square & : & 425 & & \\
\hline \multirow{2}{*}{ Phase } & \multirow{2}{*}{ System } & \multirow{2}{*}{ SG } & \multicolumn{3}{|c|}{ Lattice parameters $(\AA)$} & $\mathrm{V}$ & $\rho$ & Fraction \\
\hline & & & $\mathrm{a}$ & $\mathrm{b}$ & $\mathrm{c}$ & $\left(\AA^{3}\right)$ & $\left(\mathrm{g} / \mathrm{cm}^{3}\right)$ & $(\%)$ \\
\hline $\mathrm{Ba}_{0.8} \mathrm{Ce}_{0.2} \mathrm{Fe}_{12} \mathrm{O}_{19}$ & Hexagonal & $\mathrm{P} 63 / \mathrm{mmc}$ & $5.8907(9)$ & $5.8907(9)$ & $23.199(5)$ & $697.1(3)$ & 5.773 & 41.75 \\
\hline $\mathrm{Fe}_{2} \mathrm{O}_{3}$ & Hexagonal & $\mathrm{P} 63 / \mathrm{mmc}$ & $5.036(1)$ & $5.036(1)$ & $13.752(7)$ & $302.0(3)$ & 5.267 & 55.64 \\
\hline $\mathrm{CeO}_{2}$ & Cubic & $\mathrm{Fd}-3 \mathrm{~m}$ & $5.446(7)$ & $5.446(7)$ & $5.446(7)$ & $161.5(7)$ & 7.066 & 2.61 \\
\hline
\end{tabular}

- $\quad \mathrm{x}=0.3$

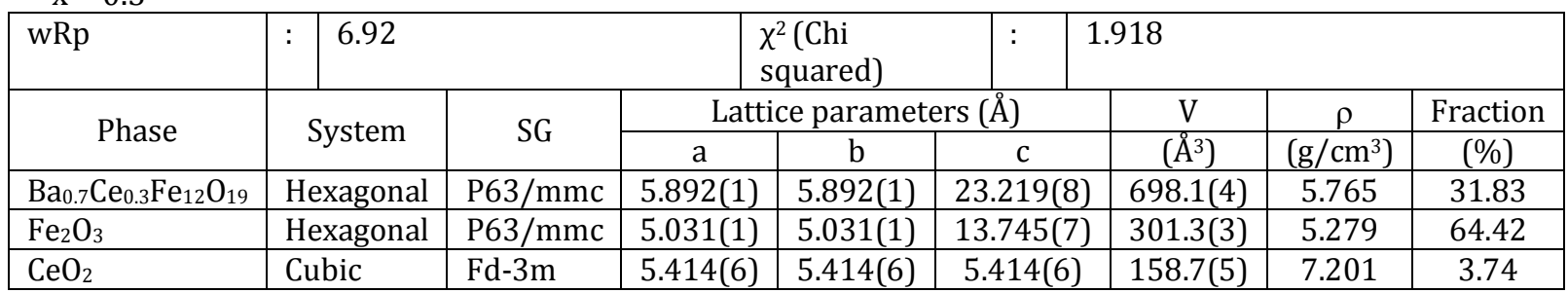

- $\quad \mathrm{x}=0.4$

\begin{tabular}{|c|c|c|c|c|c|c|c|c|}
\hline wRp & 6.76 & & & $\begin{array}{l}\text { (Chi } \\
\text { luared) }\end{array}$ & : & 699 & & \\
\hline \multirow{2}{*}{ Phase } & \multirow{2}{*}{ System } & \multirow{2}{*}{ SG } & \multicolumn{3}{|c|}{ Lattice parameters $(\AA)$} & V & $\rho$ & Fraction \\
\hline & & & $\mathrm{a}$ & $\mathrm{b}$ & $\mathrm{c}$ & $\left(\AA^{3}\right)$ & $\left(\mathrm{g} / \mathrm{cm}^{3}\right)$ & $(\%)$ \\
\hline $\mathrm{Ba}_{0.6} \mathrm{Ce}_{0.4} \mathrm{Fe}_{12} \mathrm{O}_{19}$ & Hexagonal & $\mathrm{P} 63 / \mathrm{mmc}$ & $5.890(1)$ & $5.890(1)$ & $23.197(8)$ & $697.0(4)$ & 5.774 & 22.29 \\
\hline $\mathrm{Fe}_{2} \mathrm{O}_{3}$ & Hexagonal & $\mathrm{P} 63 / \mathrm{mmc}$ & $5.033(1)$ & $5.033(1)$ & $13.737(5)$ & $301.4(2)$ & 5.279 & 73.73 \\
\hline $\mathrm{CeO}_{2}$ & Cubic & Fd-3m & $5.433(5)$ & $5.433(5)$ & $5.433(5)$ & $160.4(4)$ & 7.127 & 3.98 \\
\hline
\end{tabular}

- $\mathrm{x}=0.5$

\begin{tabular}{|c|c|c|c|c|c|c|c|c|}
\hline wRp & 6.57 & & & $\begin{array}{l}\text { (Chi } \\
\text { uared) }\end{array}$ & : & 521 & & \\
\hline \multirow{2}{*}{ Phase } & \multirow{2}{*}{ System } & \multirow{2}{*}{ SG } & \multicolumn{3}{|c|}{ Lattice parameters $(\AA)$} & V & $\rho$ & Fraction \\
\hline & & & $\mathrm{a}$ & $\mathrm{b}$ & $\mathrm{C}$ & $\left(\AA^{3}\right)$ & $\left(\mathrm{g} / \mathrm{cm}^{3}\right)$ & $(\%)$ \\
\hline $\mathrm{Ba}_{0.5} \mathrm{Ce}_{0.5} \mathrm{Fe}_{12} \mathrm{O}_{19}$ & Hexagonal & $\mathrm{P} 63 / \mathrm{mmc}$ & $5.891(1)$ & $5.891(1)$ & $23.217(1)$ & $697.8(6)$ & 5.768 & 14.98 \\
\hline $\mathrm{Fe}_{2} \mathrm{O}_{3}$ & Hexagonal & $\mathrm{P} 63 / \mathrm{mmc}$ & $5.035(1)$ & $5.035(1)$ & $13.743(3)$ & $301.8(1)$ & 5.271 & 80.81 \\
\hline $\mathrm{CeO}_{2}$ & Cubic & $\mathrm{Fd}-3 \mathrm{~m}$ & $5.433(3)$ & $5.433(3)$ & $5.433(3)$ & $160.4(3)$ & 7.126 & 4.21 \\
\hline
\end{tabular}

Table 2 shows that based on the results of refinement of X-ray diffraction patterns of $\mathrm{Ba}_{1-\mathrm{x}} \mathrm{Ce}_{\mathrm{x}} \mathrm{Fe}_{12} \mathrm{O}_{19}$ samples with variations in composition $(\mathrm{x}=0-0.5)$, samples have a single phase in the composition. $\mathrm{x}=0\left(\mathrm{BaFe}_{12} \mathrm{O}_{19}\right)$ and $\mathrm{x}=0.1\left(\mathrm{Ba}_{0,9} \mathrm{Ce}_{0,1} \mathrm{Fe}_{12} \mathrm{O}_{19}\right)$. The results of this refinement are also supported by observations of particle surface morphology for the two single phases using SEM as shown in Figure 3. In Figure 3, shows that the particle morphology of the composition $\mathrm{x}=0$ has very good and uniform particle homogeneity across the entire sample surface with the shape polygonal particles and are similar to particle morphology for the composition $\mathrm{x}=0.1$. Whereas the results of the morphological on the surface of the samples with the composition $\mathrm{x}>0.1$ did not appear homogeneous and had various particle sizes. 

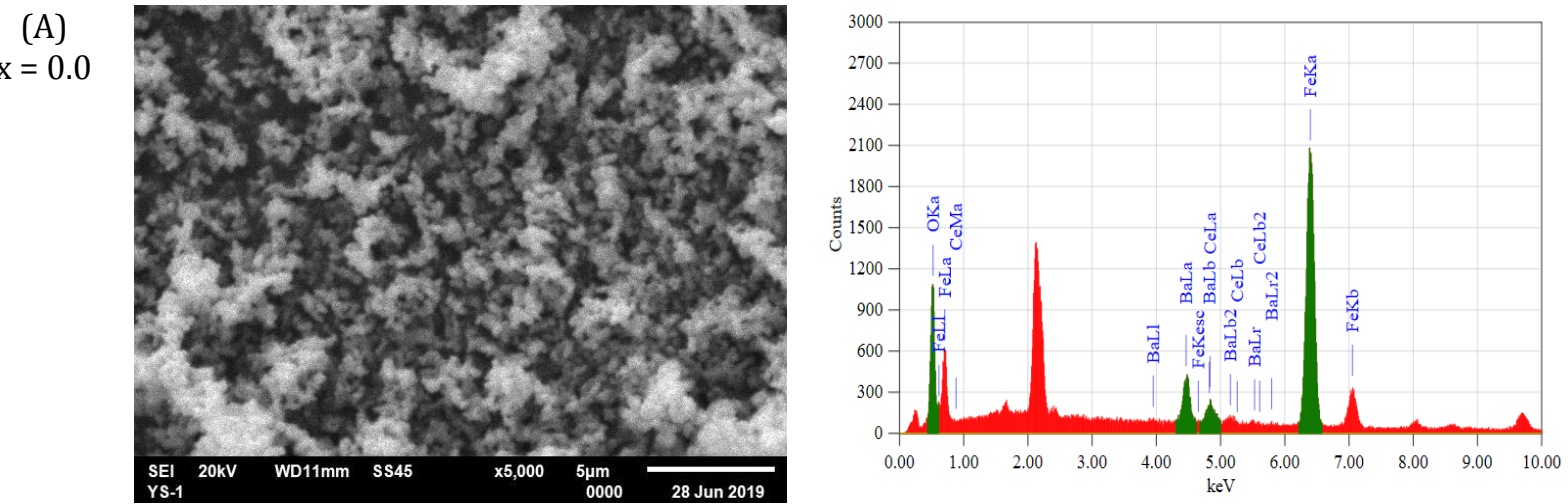

(B)

$\mathrm{x}=0.1$
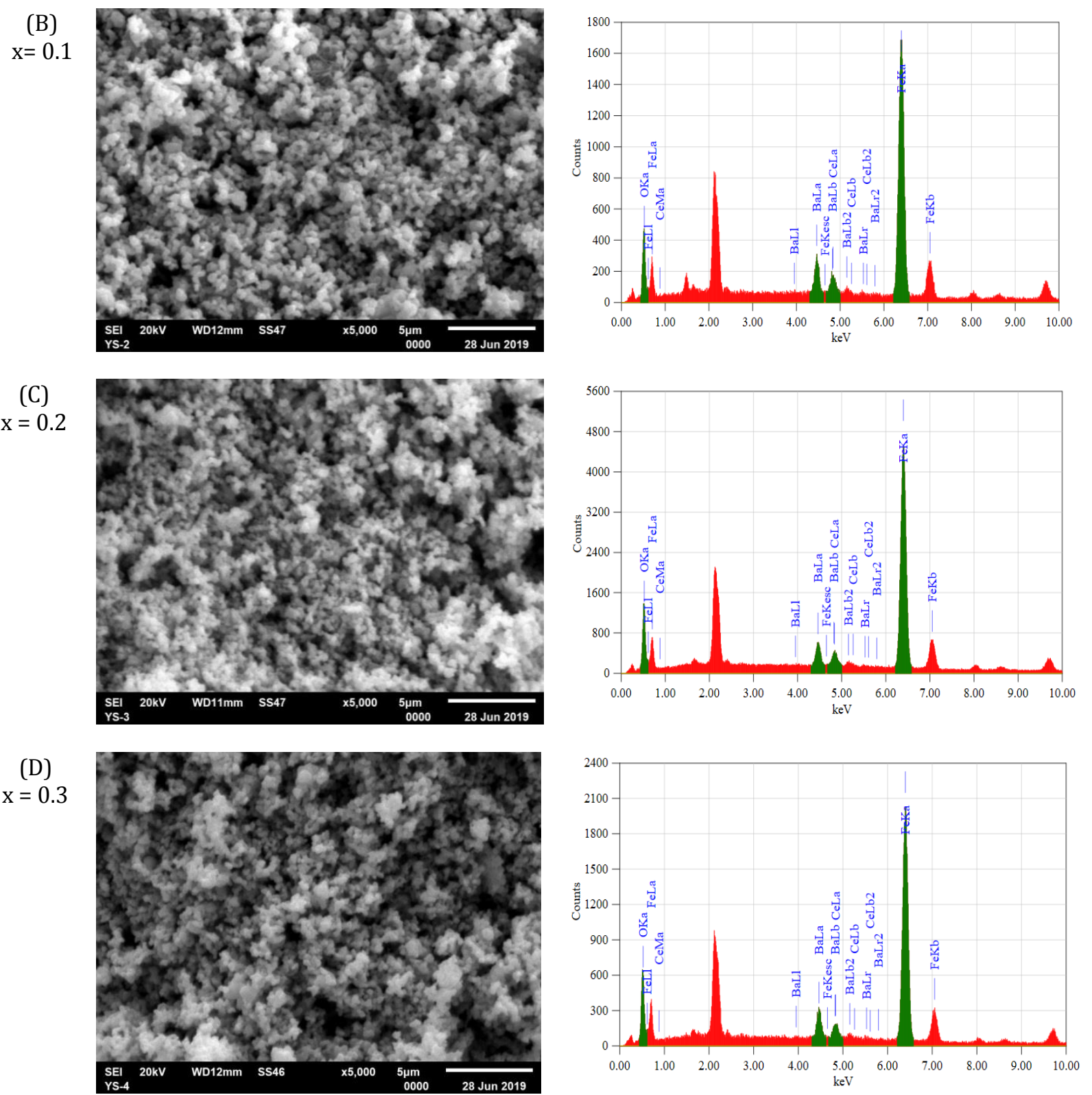

Adnyana, I. G. A. P., Sukarasa, I. K., \& Adi, W. A. (2020). Rare earth ion contribution in barium hexaferrite structure to a change of magnetocrystalline anisotropy to improving its magnetic properties. International Journal of Physical Sciences and Engineering, 4(2), 1-13. https://doi.org/10.29332/ijpse.v4n2.433 

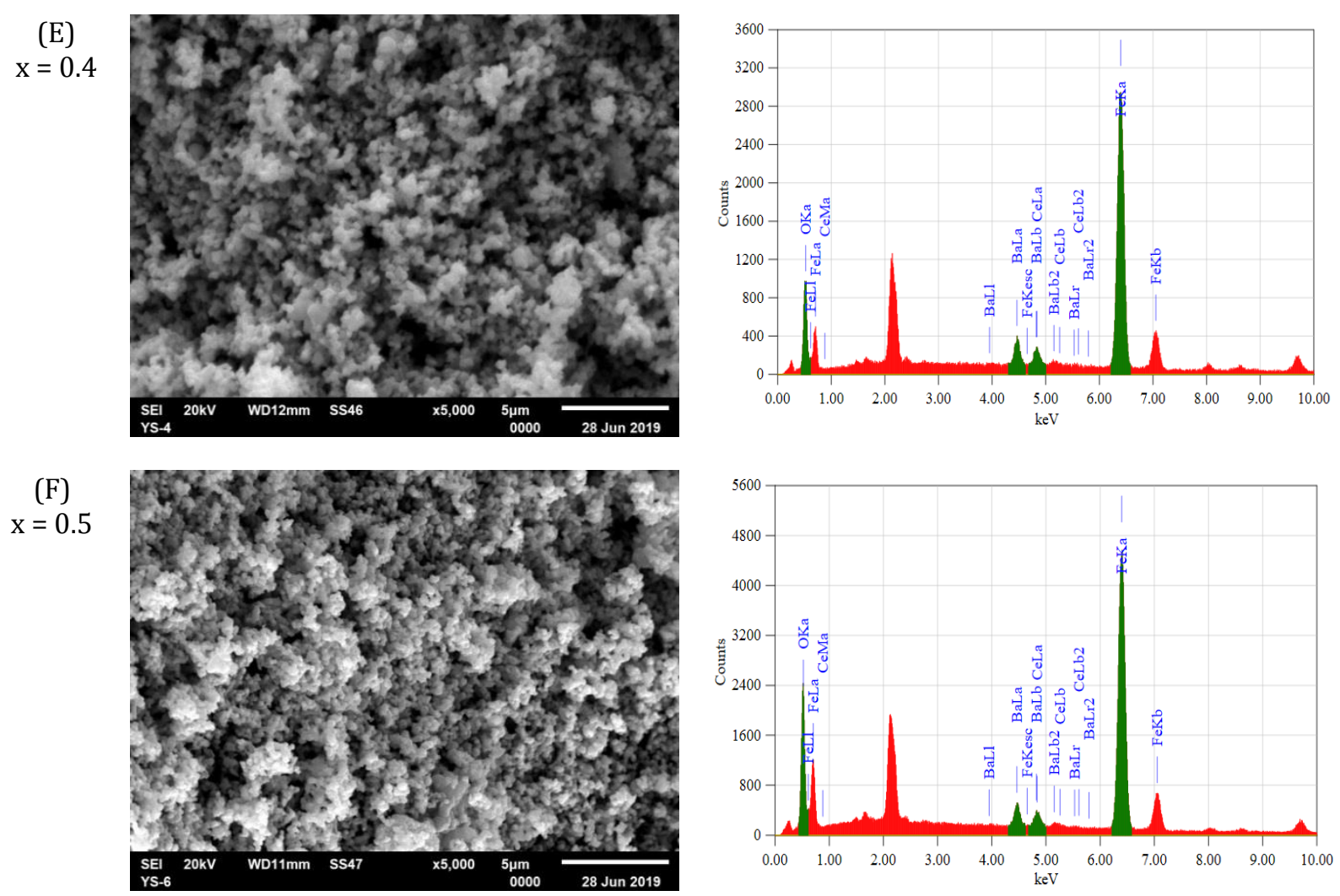

Figure 3. Morphology of sample particles observed using SEM

The results of the elementary analysis using energy dispersive spectroscopy (EDS) showed that samples with the composition $\mathrm{x}=0$ appeared to be found that the element Ce contained only elements of barium $\mathrm{Ba}$, iron $\mathrm{Fe}$, and oxygen 0 , which were at 4,464, 6,398 and $0.525 \mathrm{keV}$, respectively. Whereas the sample with composition $\mathrm{x}>0$ contains the element Ce which is at energy $4,837 \mathrm{keV}$ where the number of mass fractions increases with increasing composition $\mathrm{x}$. The detailed content of the elements present in the sample with composition $\mathrm{x}=0$ 0.5 is shown in Table 3. Based on the results of this elementary analysis, the important thing to show is that the composition $\mathrm{x}=0.1$ which has a single-phase contains the element Ce and also proves that the sample is close to the nominal composition.

Table 3

Results of elementary analysis using EDS

\begin{tabular}{cccccc}
\hline \multirow{2}{*}{ Samples $(\mathrm{x})$} & \multicolumn{5}{c}{ Elements } \\
\cline { 2 - 6 } & $\mathrm{O}(\mathrm{wt} . \%)$ & Ba (wt.\%) & Fe (wt.\%) & Ce (wt.\%) & total (wt.\%) \\
\hline 0 & 10.43 & 14.30 & 75.27 & - & 100 \\
0.1 & 9.67 & 13.63 & 75.63 & 1.07 & 100 \\
0.2 & 11.24 & 11.94 & 75.29 & 1.53 & 100 \\
0.3 & 10.65 & 10.38 & 76.72 & 2.25 & 100 \\
0.4 & 11.18 & 9.46 & 76.84 & 2.52 & 100 \\
0.5 & 11.87 & 9.34 & 75.90 & 2.89 & 100 \\
\hline
\end{tabular}

Magnetic properties were characterized using permeagraphic equipment from the external magnetic field -1.5 to 1.5 tesla and the result obtained in the form of a hysteresis curve as shown in Figure 4. Figure 4 is the relationship between the external magnetic field $\mathrm{H}$ (Tesla) and magnetization $\mathrm{B}(\mathrm{kA} / \mathrm{m})$. Based on the 
hysteresis curve, magnetic quantities can be determined, namely saturation magnetization (Bs), remanent magnetization (Br), and coercivity field (Hc). Based on the hysteresis curve, magnetic quantities can be determined, namely saturation magnetization (Bs), remanent magnetization (Br), and coercivity field (Hc). Figure 4 shows that the hysteresis curve of the six samples produced three different magnetic quantities. This means that from all compositions it produces a coercivity field (Hc), saturation, and remanent magnetization which are different and depend on several interrelated and interrelated aspects.

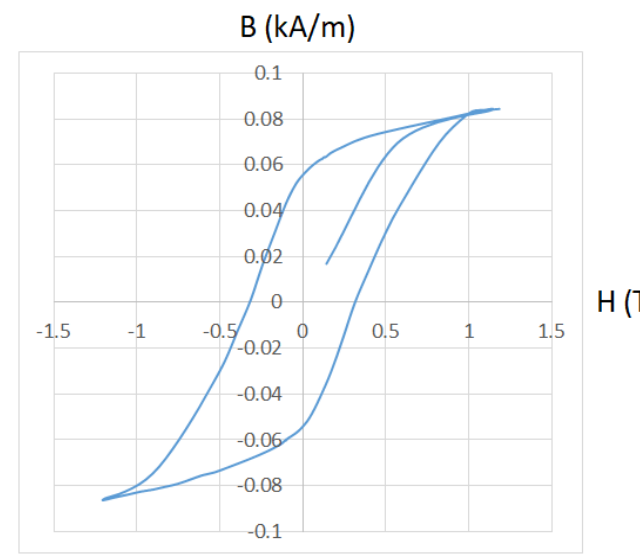

A) $x=0$

$B(k A / m)$

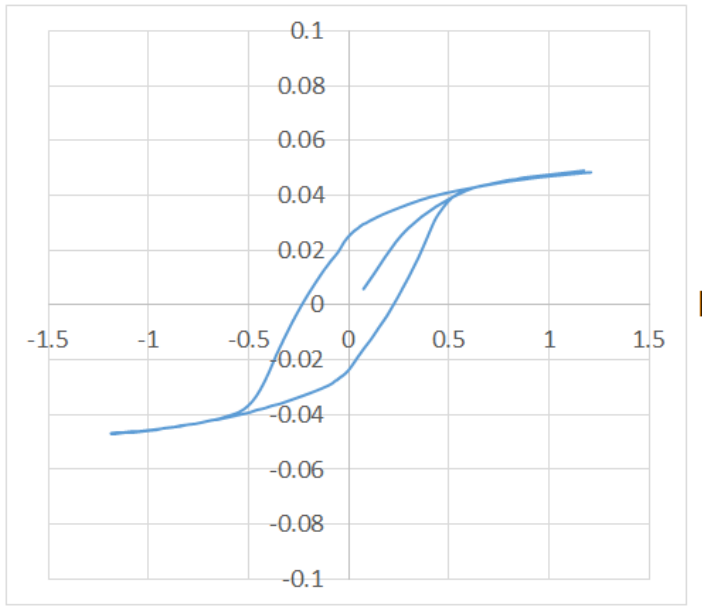

C) $\mathrm{x}=0.2$

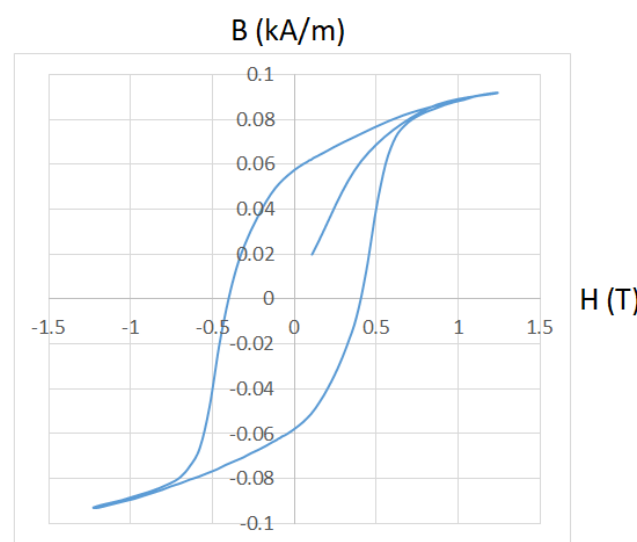

B) $\mathrm{x}=0.1$

$\mathrm{B}(\mathrm{kA} / \mathrm{m})$

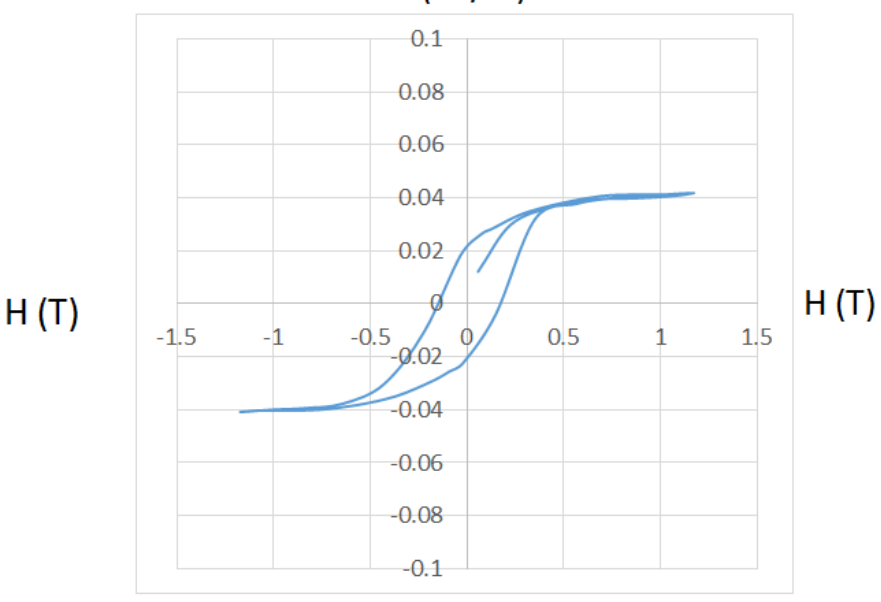

D) $x=0.3$

Adnyana, I. G. A. P., Sukarasa, I. K., \& Adi, W. A. (2020). Rare earth ion contribution in barium hexaferrite structure to a change of magnetocrystalline anisotropy to improving its magnetic properties. International Journal of Physical Sciences and Engineering, 4(2), 1-13. https://doi.org/10.29332/ijpse.v4n2.433 


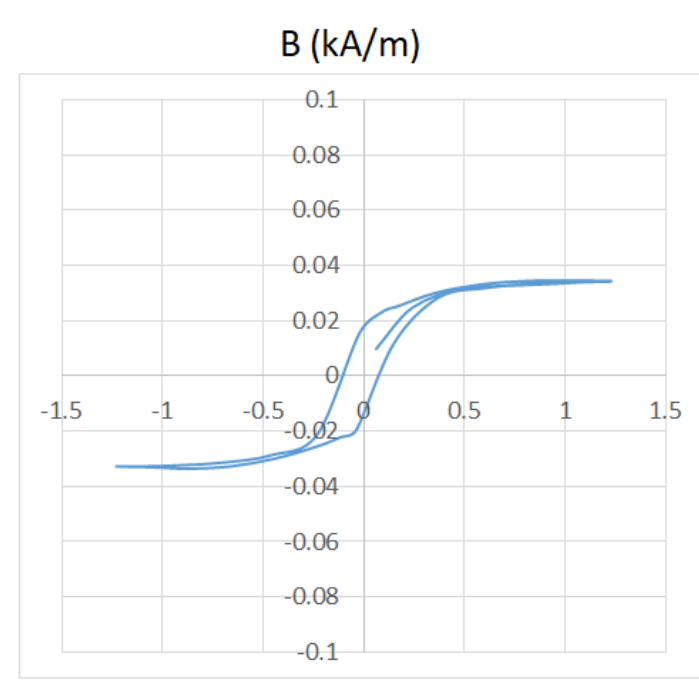

E) $\mathrm{x}=0.4$

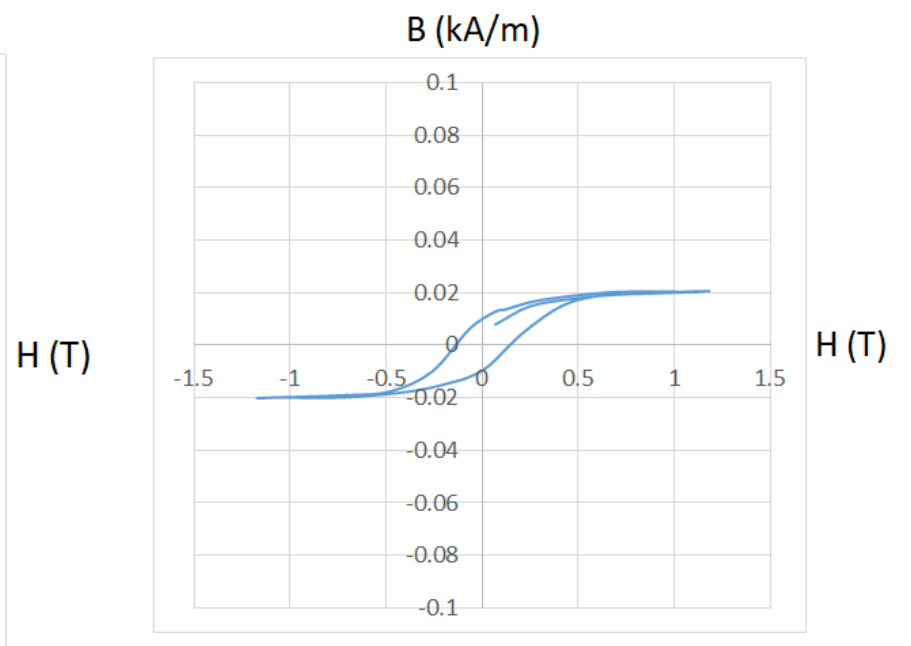

F) $\mathrm{x}=0.5$

Figure 4. Hysteresis curve of Ba1-xCexFe12019 sample measurement results using permeagraph

Based on XRD analysis results show that the mass fraction of the permanent barium hexaferrite-based permanent magnetic material decreases specifically in the composition $\mathrm{x}>0.1$, while for the composition $\mathrm{x}=0$ and $x=0.1$ the tendency of these three magnetic quantities increases as shown in Table 4 .

Table 4

Parameters of the magnetic properties of the $\mathrm{Ba}_{1-\mathrm{x}} \mathrm{Ce}_{\mathrm{x}} \mathrm{Fe}_{12} \mathrm{O}_{19}$ sample

\begin{tabular}{cccc}
\hline Sample $(\mathrm{x})$ & \multicolumn{3}{c}{ The magnitude parameter of magnetic properties } \\
\cline { 2 - 4 } & $\mathrm{Hc}(\mathrm{T})$ & $\mathrm{Br}(\mathrm{kA} / \mathrm{m})$ & $\mathrm{Bs}(\mathrm{kA} / \mathrm{m})$ \\
0 & 3151 & 0.0571 & 0.0884 \\
0.1 & 3995 & 0.0587 & 0.0917 \\
0.2 & 2375 & 0.0259 & 0.0486 \\
0.3 & 2092 & 0.0228 & 0.0415 \\
0.4 & 1870 & 0.0153 & 0.0342 \\
0.5 & 1688 & 0.0109 & 0.0206 \\
\hline
\end{tabular}

Samples with $\mathrm{x}=0.0\left(\mathrm{BaFe}_{12} \mathrm{O}_{19}\right)$ and $\mathrm{x}=0.1\left(\mathrm{Ba}_{0.9} \mathrm{Ce}_{0.1} \mathrm{Fe}_{12} \mathrm{O}_{19}\right)$ have a single phase and have the same crystal structure, namely hexagonal structure $(\mathrm{P} 63 / \mathrm{mmc})$, although with different compositions.
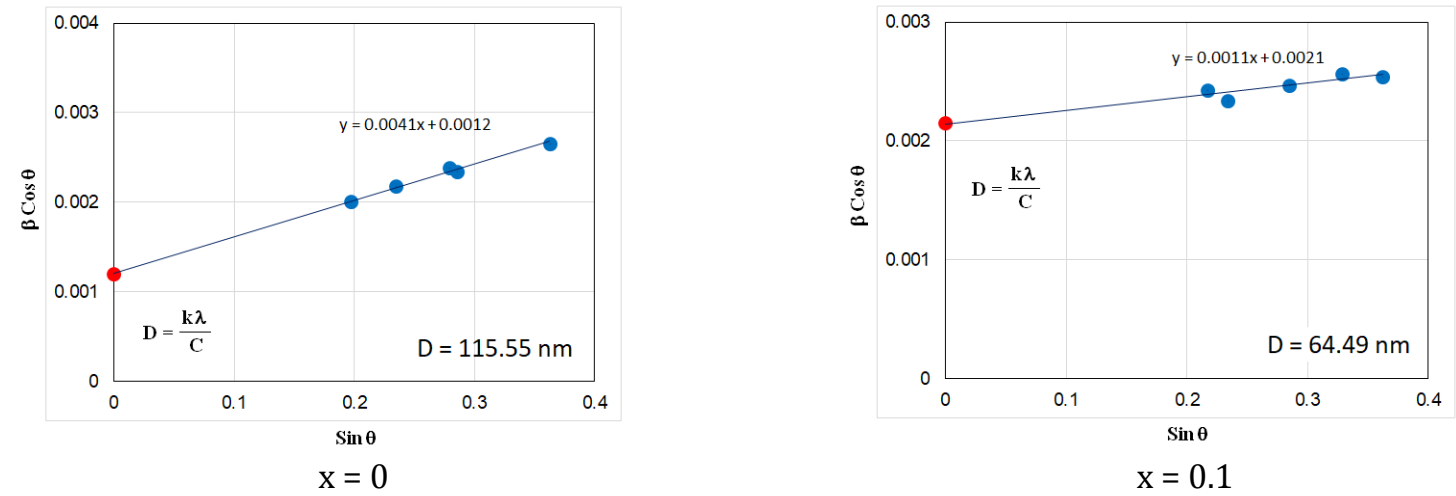

Figure 5. Calculation of crystallite size in a single-phase sample $\mathrm{Ba}_{1-\mathrm{x}} \mathrm{Ce}_{\mathrm{x}} \mathrm{Fe}_{12} \mathrm{O}_{19}$ 
At the composition $\mathrm{x}=0.1$, there are $10 \%$ Ce atoms that have succeeded in replacing some Ba atoms which turned out to have a different impact on the magnetic properties. The increase in the coercivity field for the composition $\mathrm{x}=0.1$ can be explained as related to magnetocrystalline energy or energy anisotropy. One of the factors that influence magnetocrystalline energy is the magnetic domain, where all unit cells in a crystal region have the same magnetic orientation. While the magnetic domain parameters that can be predicted simply are the size of the crystallites of each sample.

This is the simplest approach reviewed based on the calculation of crystallite size using the Williamsonhull equation as shown in Figure 5. Based on Figure 5 it can be seen that the crystallite size of the composition sample $x=0$ is greater than that of the composition sample $x=0.1$. This means that the composition of the sample $\mathrm{x}=0.1$ has a magnetic domain with a hard axis orientation which is comparatively much compared to samples with a composition of $\mathrm{x}=0$. The presence of Ce atom is thought to be able to withstand the rate of grain growth in the sample so that the grain size and grain boundary of the composition sample $\mathrm{x}=0.1$ appear smaller than the composition sample $\mathrm{x}=0$. Also, the presence of Ce can increase the value of remanent magnetization and saturation properties as shown in Table 4.

Saturation and remanent magnetization appears to increase from samples with composition.x $=0$ to samples with composition $\mathrm{x}=0.1$. There is a contribution of magnetic dipole moments in the composition sample $\mathrm{x}=0.1$ which is derived from Ce atoms which have several magnetic dipole moments in the orbital configuration $\mathrm{f}$.

So the presence of rare earth metals namely Ce atoms can enhance the magnetic properties of the material both from the magneto-crystalline anisotropy properties and the magnetic dipole moment as long as the magnetic material does not change in structure and phase.

\section{Conclusion}

The synthesis and characterization of barium hexaferrite-based permanent magnet material which has been substituted with rare earth metals namely $\mathrm{Ce}$ atom has been successfully investigated. The phase identification results show that the reaction took place perfectly and successfully formed a single-phase $\mathrm{Ba}_{1}$ ${ }_{x} \mathrm{Ce}_{\mathrm{x}} \mathrm{Fe}_{12} \mathrm{O}_{19}$ namely at the composition $\mathrm{x}=0$ and $\mathrm{x}=0.1$, while for the composition $\mathrm{x}>0.1$, the sample could not react perfectly as evidenced by the emergence of three phases, namely the $\mathrm{BaFe}_{12} \mathrm{O}_{19}$ phase, $\mathrm{Fe}_{2} \mathrm{O}_{3}$ phase, and $\mathrm{CeO}_{2}$ phase. Particle morphology in the composition $\mathrm{x}=0$ and $\mathrm{x}=0.1$ has very good and uniform particle homogeneity across the surface of the sample in the form of polygonal particles. Whereas the results of the morphology of the particle morphology with the composition.x $>0.1$ appear to be inhomogeneous and have various particle sizes. So the substitution of Ce atoms into the barium hexaferrite structure is only able at the composition limit $\mathrm{x}=0.1$. In the composition $\mathrm{x}=0.1$ has been able to increase the coercivity and magnetization fields associated with magneto-crystalline energy or anisotropy energy and the total number of magnetic dipole moments. It can be concluded that the permanent magnet with the composition $\mathrm{Ba} 0,9 \mathrm{Ce}_{0.1} \mathrm{~F}_{12} \mathrm{O}_{19}$ gives the best results.

\section{Acknowledgments}

This project was funded by Udayana University under PNBP Research grand. Thanks to the Center for Advanced Materials Science and Technology BATAN which has helped to characterize materials so that this research can be done well. In this study, I Gusti Agung Putra Adnyana and Wisnu Ari Adi were the main contributors in the completion and discussion of this paper.

Adnyana, I. G. A. P., Sukarasa, I. K., \& Adi, W. A. (2020). Rare earth ion contribution in barium hexaferrite structure to a change of magnetocrystalline anisotropy to improving its magnetic properties. International Journal of Physical Sciences and Engineering, 4(2), 1-13. https://doi.org/10.29332/ijpse.v4n2.433 


\section{References}

Adnyana, I. G. A. P., Suarbawa, K. N., Adi, W. A., Wardani, N. N. S. K., \& Jalut, L. L. S. (2019). The effect of lanthanum substitution on the coercivity field in oxide permanent magnet based on Ba1xLaxFe12019. International Journal of Physical Sciences and Engineering,3(1), 42-49. https://doi.org/10.29332/ijpse.v3n1.281

Akmal Johan, Wisnu Ari Adi, Fitri Suryani Arsyad, Dedi Setia budidaya (2019). Analysis crystal structure of magnetic materials Co Zn Fe 0, Journal of Physics: Conference Series.

Fisher, J. G., Sun, H., Kook, Y. G., Kim, J. S., \& Le, P. G. (2016). Growth of single crystals of BaFe12019 by solid state crystal growth. Journal of Magnetism and Magnetic Materials, 416, 384-390. https://doi.org/10.1016/j.jmmm.2016.04.079

Greaves, M. J., Elderfield, H., \& Klinkhammer, G. P. (1989). Determination of the rare earth elements in natural waters by isotope-dilution mass spectrometry. Analytica chimica acta,218, 265-280. https://doi.org/10.1016/S0003-2670(00)80303-7

Haritsah, I., Adi, W. A., Purwani, M. V., \& Manaf, A. (2019, March). Improved separation of Ce, La, and Nd from a concentrate of rare-earth hydroxide via fractional precipitation. In IOP Conference Series: Materials Science and Engineering (Vol. 496, No. 1, p. 012013). IOP Publishing. https://doi.org/10.1088/1757899X/496/1/012013

Haxel, G. (2002). Rare earth elements: critical resources for high technology (Vol. 87, No. 2). US Department of the Interior, US Geological Survey.

Idris, M. S., \& Osman, R. A. (2013). Structure refinement strategy of Li-based complex oxides using GSASEXPGUI software package. In Advanced Materials Research (Vol. 795, pp. 479-482). Trans Tech Publications Ltd. https://doi.org/10.4028/www.scientific.net/AMR.795.479

Lin, J., \& Jimmy, C. Y. (1998). An investigation on photocatalytic activities of mixed TiO2-rare earth oxides for the oxidation of acetone in air. Journal of photochemistry and photobiology A: Chemistry, 116(1), 63-67. https://doi.org/10.1016/S1010-6030(98)00289-5

Manaf, A., Buckley, R. A., \& Davies, H. A. (1993). New nanocrystalline high-remanence Nd-Fe-B alloys by rapid solidification. Journal of Magnetism and Magnetic Materials, 128(3), 302-306. https://doi.org/10.1016/0304-8853(93)90475-H

MV Purwani, Suyanti Suyanti, Wisnu Ari Adi, Thermal Decomposition Kinetics of Lanthanum Oxalate Hydrate Product Treatment From Monazite (2019). Journal Jusami, Indonesian Journal of Materials Science, 20(2), 50-57.

Nakamura, H., Hirota, K., Ohashi, T., \& Minowa, T. (2011). Coercivity distributions in Nd-Fe-B sintered magnets produced by the grain boundary diffusion process. Journal of Physics D: Applied Physics, 44(6), 064003. https://doi.org/10.1088/0022-3727/44/6/064003

Obradors, X., Collomb, A., Pernet, M., Samaras, D., \& Joubert, J. C. (1985). X-ray analysis of the structural and dynamic properties of BaFe12019 hexagonal ferrite at room temperature. Journal of Solid State Chemistry, 56(2), 171-181. https://doi.org/10.1016/0022-4596(85)90054-4

Taryana, Y., Manaf, A., \& Adi, W. A. (2019, July). Change of Structure and Magnetic Properties of La-Substituted Barium Hexaferrite. In Journal of Physics: Conference Series (Vol. 1282, No. 1, p. 012045). IOP Publishing. https://doi.org/10.1088/1742-6596/1282/1/012045

Terakado, Y., \& Masuda, A. (1988). The coprecipitation of rare-earth elements with calcite and aragonite. Chemical Geology, 69(1-2), 103-110. https://doi.org/10.1016/0009-2541(88)90162-3

Toby, B. H. (2001). EXPGUI, a graphical user interface for GSAS. Journal of applied crystallography, 34(2), 210213. https://doi.org/10.1107/S0021889801002242

Zepf, V. (2013). Rare earth elements: a new approach to the nexus of supply, demand and use: exemplified along the use of neodymium in permanent magnets. Springer Science \& Business Media. 


\section{Biography of Authors}

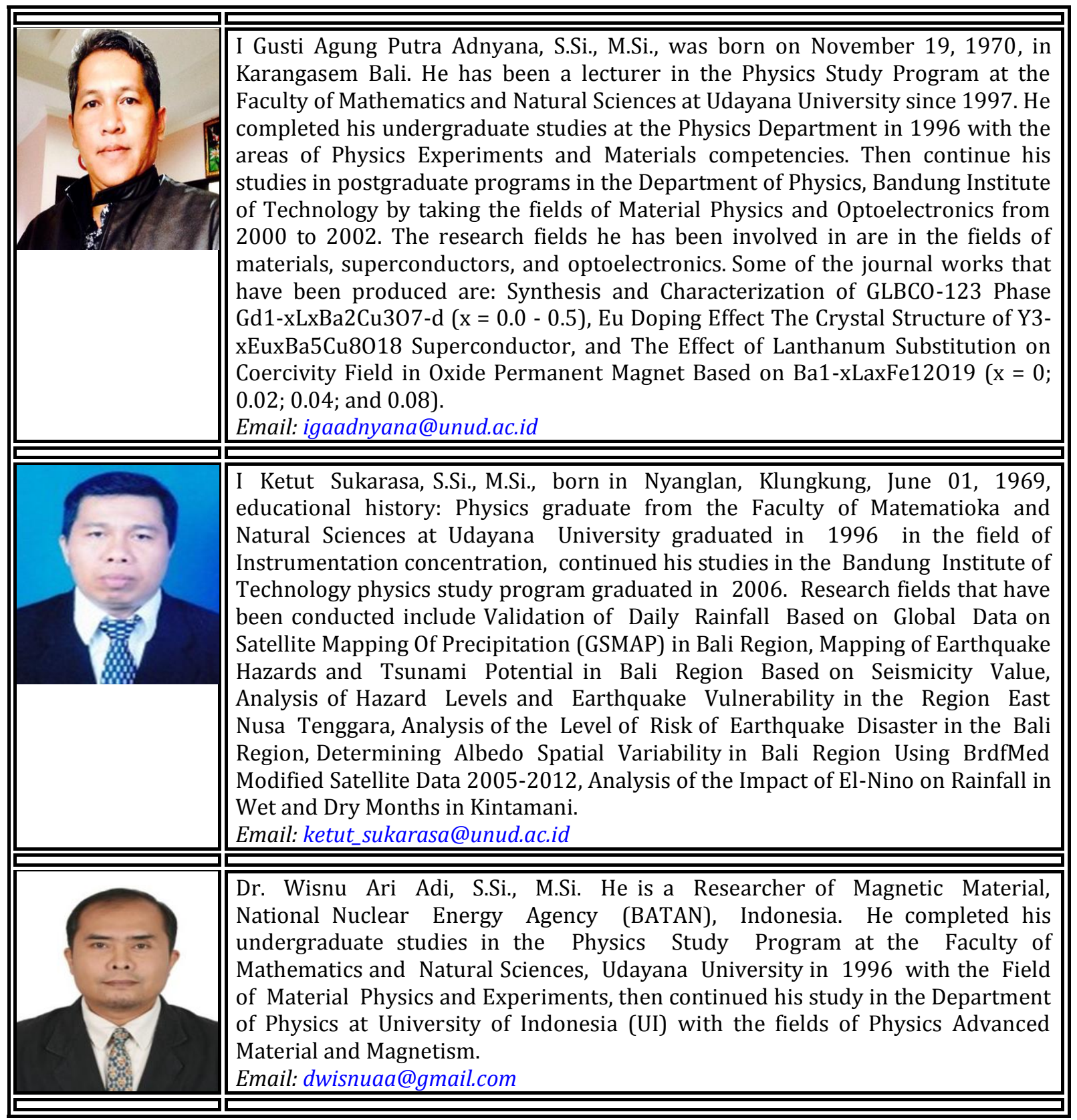

Adnyana, I. G. A. P., Sukarasa, I. K., \& Adi, W. A. (2020). Rare earth ion contribution in barium hexaferrite structure to a change of magnetocrystalline anisotropy to improving its magnetic properties. International Journal of Physical Sciences and Engineering, 4(2), 1-13. https://doi.org/10.29332/ijpse.v4n2.433 